\section{The Perceptions and Needs of Volunteers at a University- affiliated Public Garden}

\author{
Cynthia Haynes ${ }^{1}$ and \\ Cary J. Trexler ${ }^{2}$
}

AdDITIONAL INDEX WORDS. training, recognition, gardening, case study, focus groups

SUMMARY. University-affiliated gardens enhance the teaching, research, and outreach missions of the university. Attracting and retaining volunteers is challenging but important for the success of most public gardens. The objective of this case study was to determine the perceptions and needs of volunteers at a university-affiliated public garden. In a focus group format, participants' responses were analyzed to determine the benefits of volunteering to both the participants and the university. Benefits were categorized into three groups: material, solidarity, and purposive. Material benefits are tangible rewards that are equated with monetary or resource gain. Solidarity benefits are social rewards from being in a group. Purposive benefits are rewards from achieving a goal or mission. This study documents the shift of volunteer motives from deriving purposive to solidarity benefits as the garden grew and expanded. Concomitantly, the goals of the universityaffiliated garden shifted from purposive to material benefits. Our results confirm that garden volunteers are like other groups of volunteers in that they expect specific benefits for their participation, and their needs may fluctuate over time. Thus, a public garden may need to adjust reward systems to maximize the positive impact of volunteers. The university would benefit from an efficient support system to help volunteers meet their desire for helping the organization. To retain volunteers the university needs better training programs, a more flexible volunteer work schedule, and more recognition ceremonies. This study has implications for any institution that uses volunteer support to accomplish its mission.

${ }^{1}$ Assistant professor, Department of Horticulture, Iowa State University, Ames, IA 50011. Corresponding author; e-mail chaynes@iastate.edu.

${ }^{2}$ Assistant professor, School of Education, University of California, Davis, CA 95616.
$\mathrm{P}$ ublic gardens enhance teaching, research, and outreach missions of affiliated universities (Olsen et al., 1999; Stimart, 1999). Recent research shows that public gardens provide a setting for visitors to interact with others while enhancing their well-being (Hamilton and De Marrias, 2001). In most public gardens, volunteers engage in diverse projects where they gain knowledge and skills (Hamilton and De Marrias, 2001), while helping gardens achieve their missions on limited budgets (Jones, 1998). Some gardens rely entirely on volunteer support to operate. Consequently, the recruitment, training, supervision, and retention of volunteers are of utmost importance.

A high volunteer turnover rate reduces the degree to which an organization that is dependent on volunteers achieves its goals (Jones, 1998). Often, a relatively large number of volunteers choose to provide service to public gardens, but relatively few remain actively involved over the long term. Therefore, most gardens must continuously recruit and train new volunteers to enter their work force.

\section{A cost-benefit perspective}

The study of what motivates people to provide time and energy to an organization is a key component of volunteer administration (P. Murk and J. Stephan as cited in Culp, 1999). The factors that motivate volunteers have been described in various ways. For example, Atkinson and Birch (1978) defined three categories of motivation - affiliation, achievement, and power. Other researchers found that affiliation, or the desire to associate with others, was the most important incentive for adult volunteers (Henderson, 1980; Rouse and Clawson, 1992). Similarly, Culp $(1999,1997)$ found that adult 4$\mathrm{H}$ leaders were primarily motivated to volunteer by the desire for affiliation.

Motivational forces to volunteer such as affiliation, achievement, and power have been referred to in the literature both as incentives (Knoke and Adams, 1987; Wandersman and Alderman, 1993), and as benefits (Chinman and Wandersman, 1999; Rouse and Clawson, 1992). Clark and Wilson (1961) grouped volunteer benefits into three categories: material, solidarity, and purposive. Rouse and Clawson (1992) explained that 1) material benefits are tangible rewards, or something that can be equated with a monetary or resource gain;2) solidaritybenefits are intangible social rewards for group members that provide recognition and respect from being part of a group; and 3) purposive benefits are intangible rewards derived from helping a group achieve goals that are highly valued by both the volunteer and the organization.

Along with benefits, there are costs associated with participating or volunteering. In volunteer organizations, people give of their time and money (costs) in exchange for benefits. One could logically infer that, if costs exceed benefits over time for a given volunteer situation, volunteers will either discontinue service or seek other organizations that provide more benefits

The volunteer-recipient relationship can be viewed economically, where volunteers collectively produce goods for an institution (Brown, 1999). For public gardens the goods (i.e., benefits) provided for the institution by volunteers include enhanced garden maintenance, community relations, outreach, education, money, materials, etc. Costs to the garden for supporting volunteers include the time and monetary costs associated with training, supervision, administration and supply of materials. The benefits for volunteers include the acquisition of horticultural expertise (material benefits), socialization with people with common interests (solidarity benefits), and a sense of purpose (purposive benefits). Costs to volunteers include contributions of time, money, and materials. We used a cost-benefit concept to view and interpret impressions, feelings, and ideas of volunteers at a land-grant university's fledgling public garden. Many garden organizations have not examined the cost and benefits of their volunteer work force. This cost-benefit analysis will help gardens plan programs to recruit and retain volunteers.

The objectives of this study were 1) to understand the motivations of volunteers at a public garden and 2 ) to assess the costs and benefits to both parties of training, supervision, and recognition of volunteers.

\section{Materials and methods}

STUdY POPULATION AND SAMPLE. The target population for this study was about 300 public garden supporters registered at a public garden of Iowa State University. This 14-acre (5.7-ha) public garden is a collection of smaller 
gardens (rose, herb, children's, etc.) and was dedicated in 1995. A letter requesting participation in a focus group study was mailed to all supporters. Supporters were those that paid a yearly membership fee to participate in garden activities, including volunteering. Those who expressed interest in participating in this research project were scheduled into one of three focus groups. Attendance at each focus group session ranged from 9 to 12 participants, which is within acceptable range for interpretation of focus group data (Krueger, 1994). The majority of participants were female.

Data collection. A 90-min interview was conducted for each focus group. Interviews were audiotaped and transcribed and were the primary data sources. Field notes and any products created by the interviewees were consulted as secondary data.

Each focus group interview followed the format outlined by Merton et al. (1990). Two researchers attended each focus group. One researcher moderated the interview, while the other took field-notes of the discussion. Interview questions were designed to 1 ) understand the motivations for volunteering and to identify the extent of volunteer activity, 2) determine perceptions of training and supervision processes, and 3) determine perceptions of the garden recognition processes. The primary questions asked are found in Table 1. Additional questions were asked as the focus groups were conducted to follow up on answers previously given by participants and to further illuminate their perceptions and contributions.

Data analysis. Analysis of data followed the procedures of Krueger (1994) and involved three phases. First, researchers determined the trustworthiness (Lincoln and Guba, 1986; Miles and Huberman, 1994) of their initial interpretation of the interview as they read interview fieldnotes back to participants. By conducting this member check, the researchers' interpretations of the focus group members' comments helped to establish dependability and credibility of the researchers' initial impressions. In addition, the researchers discussed the interviews with each other immediately after the participants departed to underscore the salient observations that surfaced. This debriefing provided an opportunity for the impressions of each researcher to be considered.

In the second phase, the research- ers analyzed raw data from transcripts of the interviews. Discourse analysis was used (Tannen, 1989) to interpret the meaning of participants' comments as they answered interview questions. Strips of conversation from the raw interview data were coded to allow for re-assembly into the essence of shared meaning (Strauss, 1987). This initial coding was shared between researchers to ensure intercoder reliability. Changes or additions to coding schemes resulted from this crosschecking. The bins approach was used to organize data (Miles and Huberman, 1984).

The final phase of analysis was designed to reveal confirming and disconfirming patterns of evidence among individuals. To assure confirmability of the research, the researchers have provided excerpts (using pseudonyms) from the raw data that show the spirit of other participants' comments, which were the basis of interpretations.

\section{Results and discussion}

In this study we viewed and interpreted volunteer perceptions in economic terms as a cost-benefit exchange between the university garden and volunteers. During follow-up questions, the interviews revealed that the costs to volunteers were expenditures of time, labor, and material resources. Volunteers worked on committees to organize programs and tours, planted annuals and bulbs, maintained sections of the garden throughout the growing season, raised money through participation in garden plant sales, and donated personal equipment. Costs to the university were the staff time expended to train and supervise volunteers in their tasks and the money spent to purchase and maintain tools and supplies used by the volunteers. The university also incurred costs in the form of the human resources required to organize a reception by the president's wife, and the production and distribution of a newsletter containing recognition of volunteers.

Benefits to volunteers were 1) the mastery of horticultural skills and knowledge (material) 2) connectedness with their volunteer group (solidarity), and 3 ) a feeling of contribution to a worthy cause (purposive). For the university, benefits took four forms:

1) Volunteer labor maintained portions of the garden and allowed paid staff to focus on other tasks. Thus, the garden was maintained without increases in the paid labor force.

2)Volunteers nurtured community relations that led to increased financial support and recruitment of additional volunteers.

3) The outreach mission of the garden was partially fulfilled by the volunteers' organization of educational programs, tours, and activities.

4) The volunteers contributed money to purchase materials and equipment.

More in depth volunteer responses with examples of dialog have been separated into the areas of 1) motivation and volunteer activity, 2) training and supervision, and 3) recognition, since these were the primary focus areas of the interview questions.

Motivation AND VOLUNTEeR ACTIVITY. The interviews revealed that individuals expected to realize material, solidarity, and purposive benefits from volunteering at the garden. Initially the volunteers' primary motive for giving their time and expertise was purposive. They believed in the university's mission of establishing a public garden. They also mentioned that the garden's beauty enhanced their local community. They took pride in contributing to what they perceived as a gateway to their university town. For some, material benefits included volunteer hours for Master Gardener certification, while for others material benefits included shirts and calendars. In addition, participants mentioned that working at the garden

Table 1. Interview questions asked of volunteers at a university-affiliated public garden to determine their motivation for volunteering and their perceptions of training, supervision, and recognition processes.

Motivation and volunteer activity

What attracted you to volunteer at the garden?

How often do you volunteer at the garden?

Training and Supervision

What type of support has the garden provided you?

Recognition

Is there any support that the garden could provide to assist you?

How does the garden recognize your contributions?

What types of additional recognition could the garden provide? 
offered hands-on opportunities to learn and refine horticultural skills for either a vocation or an avocation.

As the garden grew, the perception of the material and purposive benefits available from volunteering at the garden declined, and the primary reason for continuing to volunteer changed. Over time, solidarity benefits became the primary motivation for volunteering at the garden. In all focus groups, participants favorably mentioned working with the friends they met at the garden.

In addition to the expectation of material, solidarity, and purposive benefits, volunteers were initially drawn to volunteer at the garden because they expected flexible and varied opportunities for contribution. This expectation was not fulfilled. Participants in each focus group reported that their work schedules often did not allow them to contribute. For example, they spoke of the garden as having only a Tuesday and Thursday morning volunteer schedule; a requirement that impeded their ability to volunteer. Respondents indicated that they would be willing to volunteer more frequently if more opportunities to contribute were both available and advertised. The frequency of volunteering varied markedly among participants. Some of the focus group members had never volunteered at the garden, while others assisted nearly twice a week. Those who volunteered were extremely dedicated to the garden; some even gave up vacation time to help.

Training and SUPERvision (sUPPORT). Focus groups were asked about their training and supervision while volunteering at the garden. Generally speaking, focus group respondents felt inadequately prepared to fulfill specific tasks and noted that there was a need for more supervision and more specific training. Respondents repeatedly stated that the training was either minimal or nonexistent. The respondents were concerned that they were not performing to the garden's standards and were uncertain as to what those standards were. Another concern was a lack of communication between garden employees and volunteers. Many commented that the superintendent or other staff channeled directions for daily tasks through other volunteers, and this process made directions and the opportunities for training unclear. Linda's comments best reflected this finding.

Linda: "When we were turned loose,
I thought that was a little risky. I mean, when I was told to go down and clean up the nicotiana, because it looked awful, but I'm not sure that's the way they wanted it done."

Other volunteers, Sharon, Diane, and Betty had similar opinions of volunteer training and communication, but were more specific.

Sharon: "The volunteer coordinators [other volunteers] talked to John, and John said to do this, and he or she says, do this, and then people kind of do that according to their interpretation."..."And we hope that its done the way John wanted it done."

Diane: "Yeah. There's a lot of trust that these volunteers know what they're doing here."

Betty: "When we were planting, though, we usually had some people planting with us, somebody to help that... knew what was expected in that plot. So we were shown then [that way] we didn't plant plants upside down."

Without adequate training and communication, volunteers believed their time was used inefficiently and some felt they could have better used their time on other activities or for other organizations. Respondents in all focus groups said that the lack of flexibility of the times they could volunteer also caused communication problems in directions for tasks. They indicated that training occurred during the morning hours, but that people volunteered as their schedule allowed. They also said that because there were no standardized procedures and that oral communication was the dominant mode of training and duty assignment, there was much room for individual interpretation of tasks.

Mistakes made by volunteers because of inadequate training and supervision led to more time and materials (cost) for the garden to correct these mistakes. Time was also lost in the growing season. Material, purposive, and solidarity benefits for volunteers were reduced under these counterproductive circumstances, inasmuch as horticultural learnings (material) were minimal and the sense of worthwhile contribution to a cause was reduced (purposive). The interviews indicated that attrition of volunteers occurred due to a decrease in perceived benefits. Certainly one could understand that volunteers who felt their time was wasted would seek other opportunities where purposive, solidarity, and material benefits could be accrued with the same or less cost.

RECOGNITION. The university recognized volunteers in the garden's annual newsletter and through a yearly reception hosted by the university president's wife. These efforts by the university were highly valued by volunteers by providing solidarity and purposiveness benefits.

However, in general, volunteers commented on the lack of recognition provided by the garden staff for their efforts. Although highly valued by the volunteers, focus group participants noted that the reception excluded many because it was held during working hours. Volunteers said that recognition could come in many forms. Many participants' comments were similar to Bob's.

Bob: "Everybody has their own method of recognition. I'm perfectly happy with a 'thank you' when I walk out the door, for just being there. Other people want publication, and even if it's hours volunteered, they want to see their name in print. And it's just human nature. Everybody fits in a category somehow. And so you basically, just like the dollar donors, in my opinion, you recognize them..."

Another volunteer, Roger, mentioned an annual recognition ceremony at the president's house.

Roger: "I think all the garden supporters were invited...not having been associated with the University...it was sort of neat to get up and say, 'Hey, I went to the (president's house), shook hands with Mrs. President, you know.' So I think that was an attempt at recognition."

An overriding concern in two of the three focus groups was a perceived value difference between those who donated time and those who donated dollars. They believed that administrators placed more value on money donors than those who donated time to the garden's operation. Participants believed that respect and recognition were lacking for their efforts as volunteers, and complained that there had been a shift in what was recognized and valued. This shift became evident to them when the garden instituted a requirement that volunteers join the garden's support organization in order to volunteer. The support organization was comprised of two types of members: those who donated only money and those who provided labor 
(plant installation, maintenance, leading tours, etc.). However, joining the support organization to provide labor required a membership fee. Volunteers expressed concern that they were being charged twice to contribute to the garden: once when they paid a membership fee for the privilege to volunteer and then a second time as they freely contributed their labor.

The supporter's organization also instituted a tiered recognition method for contributors based on the level of monetary support: the more money donated, the more recognition provided by the university. There was no parallel mechanism for those who volunteered time. As a result, some focus group respondents felt that volunteering time was not recognized equally. George and Jane's comments represent many in the focus groups.

George: "Well, I think it's insulting, and that was part of the problems with the (supporter's organization), that it got around that it's a big money organization. Don't bother to join it. You know, if you don't give $\$ 500$, you're not going to be spoken to." Jane: "I think that's too bad, because there's room for both kinds of volunteers in (supporter's organization), and one is money and the other is actually working in the garden. It brings together the people who maybe can't afford to give as well but love to do it. And I think it's too bad that that discussion ever came up."

Participants in two of the focus groups brought up the lack of recognition of volunteers university-wide. They were concerned that the university did not know how to handle volunteer donations of resources other than financial. Participants believed that the university was remiss in its efforts to recognize people for donating labor to causes such as the garden. They suggested that volunteers be recognized annually through university print media and through public ceremonies.

\section{Conclusions and \\ recommendations}

Responses of focus group participants provided insights into how logistical, training, supervision, and recognition processes could be improved to reduce costs and increase benefits to the garden and its volunteers. Logistically, garden volunteers came from all walks of life and donated differing amounts of time depending on their schedule and the garden's volunteer schedule. Because paid garden staff were required to supervise volunteers, the hours for volunteering were limited to a typical work week, and the pool of potential volunteers was inevitably reduced. Consequently, volunteers were predominantly retirees or other individuals without work responsibilities who could match their schedule with the garden's. To circumvent these logistical problems it was recommended that the garden publicize the different volunteer opportunities available and explore a more flexible schedule for volunteering. Ideally, an expanded schedule would allow volunteers to contribute at any time the garden is open.

Because the garden lacked adequate support systems and recognition processes (that reflected the values of volunteers), neither the garden nor the volunteers fully benefited from the volunteer program. There were over 300 garden supporters who met the criteria to volunteer, yet only a handful volunteered regularly. Regular volunteers were individuals with both flexible schedules and with friends who also volunteered at the garden. This suggested that solidarity was the dominant motive for regular volunteering. Initially, however, volunteers gave up time and resources because they agreed with the mission of a public garden (purposive benefit) and because they gained Master Gardener community hours (material benefit). As a sense of community developed within the garden, volunteers' motivations to contribute changed to increased expectations of achieving solidarity benefits. The shift from expectations of purposive and material benefits to those of solidarity benefits also likely occurred in part because of inadequate training and supervision and the perception of reduced ability to contribute to the cause.

More specific training and clearer communication systems would help volunteers maximize their contributions to the garden. With the ongoing expansion of this garden, there will be an increased need for human resources to ensure its proper operation. Volunteers could alleviate the need for increased paid staffing. If volunteers are to continue to play a role in this effort, then more systematic, thorough, and timely training and supervision will be needed. The combination of insufficient training and unclear communication can lead to increased mistakes, more time spent in retraining, and ultimately a decrease in volunteer self-esteem. These circumstances may reduce the benefits realized by both parties.

Specifically, it was recommended that the garden:

1) Develop a seasonal calendar of routine gardening activities tied to information pamphlets, videos, hands-on training, and supervision from staff, etc.

2) Conduct induction/orientation training for new volunteers regularly.

$3)$ Establish a centralized volunteer check-in location to facilitate communication and capitalize on training.

4) Hire a person to direct volunteer efforts, recruitment, and communication.

As a result of the university's desire for more financial resources, it established ways to reward and recognize those who donated money, but did not create a comparable system to recognize those who contributed labor. The lack of an adequate recognition system that reflected the values of those who made non-monetary contributions may have contributed to an alienation of some of the most ardent volunteers. In other words, there seemed to be a gap between the values or benefits perceived by volunteers and the university. To bridge this gap, the university garden may consider recognizing and valuing the solidarity benefits that motivate volunteers. By doing this, the university could potentially reap the material benefits it desires while nurturing a sense of community.

\section{Implications}

This study has implications for institutions desiring greater volunteer participation. By viewing and interpreting the relationship between institutions and volunteers through an economic lens, volunteer programs can be seen as an exchange function with costs and benefits for both parties. Volunteers incur opportunity costs (their time and effort) to gain the material, purposive, and solidarity benefits they desire. Institutions, in this case a universityoperated public garden, benefit from resources provided by volunteers, but these benefits do come with a price. Institutions must invest in volunteer training, supervision, and recognition systems to meet volunteers' needs. If institutions do not strategically plan 
these systems, volunteers may shop for other opportunities that will meet their needs.

\section{Literature cited}

Atkinson, J. and D. Birch. 1978. Introduction to motivation. Van Nostrand, New York.

Brown, E. 1999. Assessing the value of volunteer activity. Nonprofit Voluntary Sector Qrtly. 28(1):3-27.

Chinman, M. and A. Wandersman. 1999. The benefits and costs of volunteering in community organizations: Review and practical implications. Nonprofit Voluntary Sector Qrtly. 28(1):46-64.

Clark, P. and J. Wilson. 1961. Incentive systems: A theory of organizations. Administrative Sci. Qrtly. 6:129-166.

Culp, K., III. 1997. Motivating and retaining adult volunteer 4-H leaders. J. Agr. Educ. $38(2): 1-7$.

Culp, K., III. 1999. Recognizing tenured 4-H adult volunteers. J. Agr. Educ. 40(2): $38-45$.

Hamilton, S.L. and K. DeMarrais. 2001. Visits to public gardens: Their meaning for avid gardeners. HortTechnology 11 (2): 209-215.

Henderson, K. 1980. Programming volunteerism for happier volunteers. Parks Recreation (9):61-64.

Jones, L. 1998. Sustaining your volunteer work force. Public Garden 13(4):41-44.

Kanter, R. 1968. Commitment and social organizations: A study of commitment mechanisms in utopian communities. Amer. Sociol. Rev. 33(4):499-517.
Knoke, D. and R. Adams. 1987. The incentive systems of association. Res. Sociol. Org. 5:283-309

Krueger, R. 1994. Focus groups: A practical guide for applied research. SAGE Publ., Thousand Oaks, Calif.

Lincoln, Y. and E. Guba. 1986. But is it rigorous? Trustworthiness and authenticity in naturalistic inquiry, p. 144-151. In: D.D.Williams (ed.). Naturalistic evaluation. Jossey-Bass, San Francisco.

Merton, R., M. Fiske, and P. Kendall. 1990. The focused interview. Free Press, Glencose, Ill.

Miles, M. and A. Huberman. 1994. Qualitative data analysis: An expanded sourcebook. 2nd ed. SAGE Publ., Thousand Oaks, Calif.

Olsen, S., B. Amundsen, D. Varga, P. Minch, and D. Anderson. 1999. The Utah Botanical Gardens: An educational resource for the university and the community. HortTechnology 9(4):562-565.

Rouse, S. and B. Clawson. 1992. Motives and incentives of older adult volunteers. J. Ext. 30(2). I Aug. 2002 . <http:// www.joe.org/joe/1992fall/al.html>.

Stimart, D. 1999. Development and integration of an instructional garden in education at the University of Wisconsin- Madison. HortTechnology 9(4):557-561.

Strauss, A. 1987. Qualitative analysis for social scientists. Cambridge Univ. Press, Cambridge, Mass.

Tannen, D. 1989. Talking voices: Repetition, dialogue, and imagery in conversational discourse. Cambridge Univ. Press, Cambridge, Mass.

Wandersman, A. and J. Aldermen. 1993. Incentives costs and barriers for volunteers: A staff perspective on volunteers in one state. Rev. Public Personnel Admin. 8(1):67-76.

\section{Assessing Consumer Knowledge and Use of Landscape Plant Health Care and Integrated Pest Management Practices through a Computer-based Interactive Survey}

\author{
James C. Sellmer, \\ Kathleen M. Kelley, ${ }^{1}$ \\ Susan Barton, ${ }^{2}$ and \\ David J. Suchanic ${ }^{3}$
}

AdDITIONAL INDEX WORDS. cluster analysis, IPM, PHC, Philadelphia Flower Show, segmentation, survey

Summary. Attendees at the 2001 Philadelphia Flower Show participated in an interactive-quiz-formatted survey on touch-screen computers to determine their knowledge and use of plant health care (PHC) and integrated pest management (IPM) practices. Participants answered 15 questions in three categories: 1) PHC practices (criteria for proper plant selection, correct planting practices, and reasons for mulching and pruning); 2) IPM practices (insect identification, plant and pest monitoring, and maintenance of records on pests found and treatments applied to their landscape plants); and 3) demographic and sociographic questions to aid in characterizing the survey population. Over half of the participants $(58 \%)$ were interested in

Journal Paper 425 of the Pennsylvania State Univ., Dept. of Horticulture. This research was funded in part by the Pennsylvania Horticultural Society (PHS), Philadelphia and the Penn State University, Dept. of Entomology, Integrated Pest Management (IPM) to Dr. Robert Berghage and Mr. Martin McGann for reviewing an earlier draft of the manuscript. Use of trade names in this publication does not imply endorsement of products named nor criticism of similar ones not mentioned

${ }^{1}$ Assistant professor, Dept. of Horticulture, Penn State Univ., Univ. Park, PA 16802.

${ }^{2}$ Extension specialist, Dept of Plant and Soil Sciences, Univ. of Delaware, Newark, DE, 19717-1303.

${ }^{3}$ Ornamental horticulture extension agent, Montgomery County, 1015 Bridge Road, Suite H, Collegeville, PA, 19426 